\title{
Measuring Readiness and Success at a Higher Education Institution
}

\author{
Juan-Claude Lemmens \\ Gerhard I. du Plessis \\ David J.F. Maree \\ University of Pretoria
}

\begin{abstract}
Address correspondence to Juan-Claude Lemmens, Ph.D., Department for Education Innovation, University of Pretoria, Pretoria 0002, South Africa. Email: jlemmens@up.ac.za
\end{abstract}

This study investigated readiness as a correlate of academic success among beginning university students. A total of 829 first-time entering students from a large business sciences faculty were participants (males = 319, females = 510, mean age $=19, \mathrm{SD}=0.50$ years). They completed the Academic Readiness Questionnaire (Lemmens, 2010) during the first-year orientation week. Data on academic success, consisting of subject marks and credits were collected in 2009 after a results verification process. Data were analysed with three separate multiple regression analyses. The first analysis consisted of the overall student sample, the second and third consisted of the black and the white students separated from the overall student sample. The main findings reveal that high school marks, the number of subjects in first year (credits registered), goal orientation, race, learning-efficacy, gender and the geographical area of high school have a direct relationship with academic success. The variables that predict academic success for black students are high school marks, credits registered, and parental education. The variables that predict academic success for white students are high school marks, goal orientation, credits registered, learning-efficacy, gender, and parental education.

Keywords: Achievement motivation, academic success, first-year student, goal orientation, non-cognitive, readiness for university

Higher education in South Africa has been subjected to rapid changes since the formation of a democratic dispensation in 1994 (CHE, 2004). After sixteen years of democracy shortcomings are still evident in the higher education system. These include the limited 'pool' of students with endorsement for higher education, the low participation rates overall and the low throughput rates of students entering universities, especially black and biracial students (Scott, Yeld, \& Hendry, 2007; Scott, 2009; CHE, 2009).

During the period 2005 to 2007 , the overall participation rates remained constant at $16 \%$. Student enrolments are frequently transformed to participation rates or Gross Enrolment Rate (GER) in order to compare countries with one another and are often used to inform educational policy. Participation rates are calculated based on the total number of students enrolled in higher education (of all age's groups) in a given year, expressed as a percentage of the 20 to 24 year-old age group of the population (Scott, 2009; Scott et al., 2007). Black and biracial students' participation rates remained constant at $12 \%$. Participation rates for the white and Indian students were 54\% and $43 \%$ respectively at the time (CHE, 2009).

Scott et al. (2007) indicate the reason for low participation rates of black students specifically is because of the shortage of candidates with endorsement for higher education (only $5 \%$ of 1995 grade 12 cohort) and the low number of black students passing physical and mathematical sciences on higher grade (26.8\% of students in 2003). Furthermore, students are generally under-prepared for higher education, even though they enjoy endorsement for higher education (Scott et al., 2007; Strydom as cited in Joubert, 2002). Under-preparedness refers to students who are in general academically under-prepared and more specifically under-prepared in reading, writing and mathematics skills (Van Dyk \& Weideman, 2004).

Under-preparedness in general could be the symptom of questionable 2007 Senior Certificate results for English first additional language, Accounting, Business Studies and Economics (Umalusi, 2009; 2010). Umalusi describe the documentation of the curricula as scant in providing teaching guidance or methodology and to 'sketchy' internal and external assessment guidelines (Umalusi, 2010). The availability of information and possible inconsistencies across provinces could have favoured well-resourced schools and highly skilled teachers, which divides learning experiences among racial groups in high school even further. The current situation certainly limits the possibility of delivering on the high demand for financial service professionals needed in the market place, especially in terms of equitable outcomes.

\section{Conceptual Framework}

According to Kuh, Kinzie, Buckley, Bridges, \& Hayek (2007) an institution must understand and know its students when they arrive at the university (also refer to Braxton \& Hirschy, 2005). Determining students' readiness for university education is seen as the first step in understanding the students that enrol at an institution. Readiness for university education can be defined as the level of preparation a student needs in order to enrol and succeed, without remediation in a credit-bearing programme at a higher education institution (Conley, 2007, p.1). Readiness for university education is predominantly associated with high school academic achievement and frequently also the results of admission tests (Byrd \& MacDonald, 2005; Conley, 2007). In addition to academic achievement, the participants of Byrd and MacDonald's study indicated additional factors associated with 
readiness, namely (a) skills in time-management, (b) motivational factors and (c) background factors and (d) student self-concept (Byrd \& MacDonald, 2005; Conley, 2007). High school achievement and ability tests measure cognitive skills and strategies as well as content knowledge (Conley, 2007). According to Conley (2007), these elements are very important indicators of students' readiness for university education. However, when students enrol to university they bring with them personal attributes, academic ability, and other socio-cultural characteristics, just to name a few (Tinto, 1993). A broader definition of preparedness or readiness is therefore necessary to screen students at risk, compared to using only cognitive ability.

The readiness model of Conley (2007) is explained firstly to show that readiness for university education is not only associated with academic performance in school or with measures of ability on psychometric tests, but also with socio-cultural and motivational factors.

\section{The Conley Model}

Conley (2007) suggests a broad definition of readiness that includes inter-related cognitive strategies, acquiring content knowledge, academic behaviours, and contextual knowledge and skills. Cognitive strategies include conceptual and evaluative thinking, synthesising and problem solving (also refer to Conley et al., 2009). These strategies develop over time and are necessary to attain academic success at university. Content knowledge is the skills that are inherently part of specific high school subjects, such as critical reading skills in English language studies. It is dependent on developing and using cognitive strategies because it is through the use of key cognitive strategies that content knowledge is achieved (Conley, 2005; 2007). Academic behaviours consist of meta-cognitive skills and study skills (Conley, 2007). The meta-cognitive skills compose of self-awareness, self-monitoring and self-control. The study-skill behaviours compose of time management, which according to Conley (2007) refers to planning a task, setting up the study environment, breaking up the tasks into manageable chunks and balancing competing tasks. Lastly, contextual knowledge and skills refers to the ability to adapt and understand the context or climate of the institution. Accordingly, students who do not understand or who are unable to adapt to the norms, values and expectations of the institution are more likely to feel alienated and have intentions to withdraw voluntarily (Conley, 2007). Another important area of contextual awareness is known as 'college knowledge' (Conley, 2007). College knowledge refers to an understanding of the bureaucratic processes that are associated with applying, enrolling and studying at a university (Bean \& Eaton, 2000; Conley, 2007). For success in higher education, students must acquire appropriate institutional culture through transition learning.

Schlossberg, Waters, \& Goodman (1995) differentiates between three types of transitions, namely anticipated transitions, unanticipated transitions and non-event transitions. An anticipated event could simply refer to a graduating high school student deciding to enrol at a university for a specific degree. Examples of an unanticipated or a non-event transition relate to the loss of anticipated aspirations due to financial pressures or changes in career aspirations. In the event of any type of personal transition, the evaluation of the transition is vital to how one think, feel and cope with the transition or non-event. For instance a first entry college student must take up the role of being a student. Bean and Eaton (2000) indicate that the first semester is generally regarded as a period of transition were students have to adjust to the new institutional environment as well as manage increased levels of stress (Hawkins \& Larabee, 2009; Tinto, 1993; Upcraft, Gardner, \& Barefoot, 2005).

Conley (2007) suggest that students who are ready for university education are more likely to have a 'smoother' transition phase, be academically successful, and persist. These students are more able to adapt to the university environment because they are able to strengthen their resources (Schlossberg et al., 1995). These resources consist of a support structure and personal psychological resources and strategies. Successful college transition is likely with persistence, increasing effort, and being more engaged (Geiger \& Cooper, 1995).

Readiness characteristics consisting of cognitive, demographic and psycho-social variables are regarded as important indicators of academic success. Institutions who understand the entering student, including the between and within-group differences, are more likely to address the needs of individual students with pro-active interventions (Beck \& Davidson, 2001; Seidman, 2005). A scientific approach to measuring the readiness characteristics is of importance in planned interventions of potentially at-risk students.

\section{Goals of the Study}

The goal of this study was to determine the readiness characteristics that predict the academic success of two different racial groups (black and white students) in the first academic year in a large business sciences faculty. The readiness characteristics consist of cognitive, demographic and psycho-social variables, which are informed from the literature review. The following research questions apply:

- What is the relative contribution of individual readiness characteristics in predicting academic success at first-year for each of the groups?

- Which is the best predictor of academic success for each of the groups?

- How well do the readiness characteristics predict academic success for each of the groups?

\section{Method}

\section{Participants and Setting}

The University of Pretoria is a large, research intensive 'contact' institution. In 2008, student numbers totalled 57409. Pre-1994 the university was characterised as a 'Historically White (Afrikaans) University' (Bunting, 2006a), but is currently a dual medium university that provides tuition in both Afrikaans and English. A convenience sample of 829 students participated in the study. The target group reflects the 2008 intake of first-time entering students at the Faculty of Economic and Management Sciences. The Faculty of Economic and Management Sciences is the largest faculty amongst eight other faculties and contributed $24.6 \%$ of all undergraduate enrolments in 2008.

The sample in terms of racial differentiation consisted of 202 black (24.4\%), 21 biracial (2.5\%), 22 Indian (2.7\%) and 584 white $(70.4 \%)$ students. Biracial and Indian students had to be discarded from further analysis where race is to be included as an independent variable because of their low numbers. 510 $(61.5 \%)$ female and $319(38.5 \%)$ male students participated. High school marks is a continuous variable ranging from 1 to 30 . It is categorised for representation purposes in a low (24.7\%), medium (46.7\%) and high M-score (28.6\%) group. 


\section{Data Collection}

Participants completed the Academic Readiness Questionnaire (ARQ: Lemmens, 2010). The ARQ is a 66 item Likert -type self-report measure of psycho-social constructs related to academic readiness (1 Definitely disagree to 5 Definitely agree). The overall Cronbach's alpha for the ARQ with the research sample was 0.87 , which indicates good internal consistency reliability for the scale (Pallant, 2007).

The Academic Success measure comprised student marks in registered first-year subjects at the end of the 2008 academic year. The marks were expressed as a ratio which consists of the number of credits passed over the number of credits prescribed by the faculty. Students were awarded the full credit load for a subject passed. The total credits passed were tallied and divided by the number of credits prescribed. Credits registered refer to the number of credits students registered for in their first academic year. In the beginning of each academic year, students register for a number of subjects with assigned credits based on the notional hours that students have to spend on each subject in a programme. This variable does not take account of the prescribed number of credits by programme or the number of credits that were failed or passed.

\section{Demographics}

Demographic information of the students was sourced from the student database. The definitions of the ARQ factors and demographic variables mined from the student database of the university are represented in Table 1.

\section{Procedure}

Assessment sessions were arranged at the beginning of the academic year during the welcoming week of the university. Participants were informed that the goal of the research was to investigate students' academic readiness for university education and how these characteristics predict academic success.
The participants were informed that participation is voluntary and that individual student information will not be disclosed. The data was collected from participants registered at the Faculty of Economic and Management Sciences during two one hour sessions. Permission to administer the questionnaire was obtained from the programme coordinator prior to administration.

\section{Data Analysis}

Multiple regression analyses were used to determine the relationship between the independent variables with the dependent variable, academic success (Tabachnick \& Fidell, 2007). A regression analysis indicates the net effects of each variable in a regression equation and thus shows the relative importance of each independent variable. The independent variables were either continuous or dichotomous. 'Distance of school' consisted of three categories, namely 'Pretoria', 'Gauteng' and 'other provinces'. Pretoria and Gauteng were collapsed into one variable called 'Gauteng province' to make 'distance of school' a dichotomous variable. 'Home language' and 'preferred language of tuition' were not added because of its covariance with race.

\section{Results}

In the next section the influence of the readiness characteristics on academic success will be discussed, firstly the sample as one group, followed by the black and the white student group.

\section{The Sample Group}

Standard multiple regressions were used to determine the variance explained in the dependent variable, 'academic success' for the overall student group. The $\mathrm{R}^{2}$ adjusted of 0.38 indicate that more than a third of the variance in academic success is explained by the independent variables. The overall student group's model reached statistical significance at $p \leq 0.001(F(12)$ $=32.9$ ), indicating that the independent variables in the model

Table 1

Defining the Independent and Dependent Variables

Independent Variables Definition

Achievement motivation orientation

The degree to which one has an intrinsic interest in higher education and an expectation to achieve academically.

Learning-efficacy

The degree of confidence in one's own ability to achieve one's academic goals.

Goal orientation

The degree to which one is able to plan for learning by setting task-specific goals.

Integration/support

The degree to which a student experience institutional, social, family and financial support.

Reading behaviour The degree to which one enjoys reading for pleasure.

M-score (High school marks)

An aggregate score based on the six best senior certificate subjects and ranges between 0 - 30.

Credits registered

A frequency count of the number of credits registered during the first-year.

Parental education at UP One or both parent(s) completed a degree at the University of Pretoria.

Housing Where a student lives while attending university.

Distance of school

Distance of school from the university, clustered by Province.

Dependent Variables

Definition

Academic success

Ratio representing the number of credits passed over the number of credits prescribed by the programme. 
are significant predictors of academic success. In this model, seven variables explained academic success with statistical significance. M-score, credits registered, goal orientation, and race are highly significant $(p \leq 0.001)$ in explaining academic success, as were learning-efficacy, gender, and distance of school ( $p \leq 0.05$ level).

The variable with the largest beta weight was M-score (0.593), followed by race $(0.255)$, credits registered $(0.149)$, goal orientation $(0.131)$, learning-efficacy $(-0.085)$, gender (0.081), and distance of school $(-0.068)$. By squaring the zero-order correlation the variance of each variable can be determined. According to the zero-order correlations $(r)$ the variance of $38 \%$ can be accounted for almost entirely by M-score, with a zero-order correlation of 0.547 . The rest of the variance is explained by race $(0.122)$, credits registered $(0.162)$ and goal orientation $(0.166)$ followed by the last of the three variables, thus indicating the importance of high school achievement (M-score) in the model.

Predicting academic success would be possible by using the $B$ coefficients in the following equation:

Academic success $=0.034^{\star} \mathrm{M}$-score $+0.002^{*}$ Credits registered $+0.047^{\star}$ Gender $+0.175^{\star}$ Race $+0.006^{\star}$ Goal orientation $-0.004^{*}$ Learning-efficacy.

The size and direction of the relationships suggest that academic success is associated:

- with black students;

- with a high M-score;

- with students registered for the prescribed or more programme credits;

- with higher scores on the goal orientation scale; and

- with students who attended schools from Gauteng province (closer to the university).

Even though learning-efficacy and gender produced significant results there was an inconsistency in the direction of the beta weight and the zero-order correlation, making interpretation of this variable difficult for the overall student group.
Race, as a variable, was split between black and white students with the 'Split-file' option in SPSS.V17® to allow for separate multiple regression analyses between the two racial groups. The same variables were used as in the student sample regression model, except for race, that was excluded.

\section{Black Student Group}

Standard multiple regressions were used to determine the variance explained in the dependent variable, 'academic success' for black students. The $\mathrm{R}^{2}$ adjusted is 0.289 , indicating that $29 \%$ of the variance is explained by the model. This model reached statistical significance at $p \leq 0.001\left(F_{(11)}=5.9\right)$. In this model there were three variables that were statistically significant in explaining academic success for black students. The variable with the largest beta weight was M-score $(0.463)$, followed by credits registered (0.203) and parent education at UP $(0.175)$. According to the squared zero-order correlations $(r)$ the variance of $29 \%$ can be accounted for almost entirely by M-score, with a zero-order correlation of 0.432 . The rest of the variance is explained by credits registered (0.303) and parent education at UP (0.093).

\section{White Student Group}

Standard multiple regressions were used to determine the variance explained in the dependent variable, 'academic success' for white students. The $\mathrm{R}^{2}$ adjusted is 0.404 , indicating that $40 \%$ of the variance is explained by the model for white students. This model reached statistical significance at $p \leq 0.001$ $\left(F_{(11)}=30.8\right)$. In this model there were six variables that were statistically significant in explaining academic success. The variable with the largest beta weight was M-score (0.631), followed by goal orientation $(0.133)$, credits registered $(0.132)$, learning-efficacy $(-0.114)$, gender $(0.102)$, and parent education $(-0.090)$. According to the zero-order correlations $(r)$ the variance of $40 \%$ can be accounted for almost entirely by M-score, with a zero-order correlation of 0.601 . The rest of the variance is explained by credits registered $(0.167)$ and goal orientation (0.157) followed by the last of the four variables.

\section{Table 2}

Regression Results for Academic Success for the overall Student Group, Black Students and White Students

Dependent variable: Academic success

\begin{tabular}{|c|c|c|c|c|c|c|}
\hline \multirow[b]{2}{*}{ Independent variables } & \multicolumn{2}{|c|}{ Overall student group } & \multicolumn{2}{|c|}{ White students } & \multicolumn{2}{|c|}{ Black students } \\
\hline & Beta & Zero-order r & Beta & Zero-order r & Beta & Zero-order $r$ \\
\hline Achievement motivation & -0.010 & 0.059 & 0.027 & 0.039 & -0.138 & -0.065 \\
\hline Learning-efficacy & $-0.085^{\star}$ & 0.069 & $-0.114^{*}$ & 0.071 & 0.006 & 0.053 \\
\hline Goal orientation & $0.131^{\star *}$ & 0.166 & $0.133^{\star}$ & 0.157 & 0.119 & 0.127 \\
\hline Integration and support & -0.033 & -0.054 & -0.037 & -0.041 & -0.052 & 0.064 \\
\hline Reading behaviour & -0.058 & 0.050 & -0.039 & 0.028 & -0.150 & -0.138 \\
\hline Credits registered & $0.149^{* \star *}$ & 0.162 & $0.132^{\star * \star}$ & 0.167 & $0.203^{*}$ & 0.303 \\
\hline M-score (High school achievement) & $0.593^{\star * *}$ & 0.547 & $0.631^{* * *}$ & 0.601 & $0.463^{\star \star *}$ & 0.432 \\
\hline Gender & $0.081^{*}$ & -0.042 & $0.102^{\star *}$ & -0.053 & 0.059 & 0.093 \\
\hline Distance of high school & $-0.068^{*}$ & -0.019 & -0.060 & -0.034 & -0.103 & -0.157 \\
\hline Race & $0.255^{\star * *}$ & 0.122 & - & - & - & - \\
\hline Residence & -0.004 & 0.046 & -0.013 & 0.010 & 0.061 & 0.105 \\
\hline Parental education at UP & -0.054 & -0.060 & $-0.090^{\star}$ & -0.054 & $0.175^{\star}$ & 0.093 \\
\hline
\end{tabular}

Note. ${ }^{\star}=p \leq 0.05,{ }^{* *}=p \leq 0.01,{ }^{* \star *}=p \leq 0.001$ 
Both the beta weights and zero-order correlations of the three models point to an average positive relationship between credits registered and academic success. Thus, indicating that students registering for more credits are more successful academically. A cross-tabulation with a Chi-square 'goodness-of-fit' test showed statistical significant differences between the number of credits registered (binned in thirds with SPSS.V17® Visual Binning option) and academic success (binary variable fail/pass) with Pearson's Chi-square $\leq 0.001, d f(2)$. The cross-tabulation indicate that the students who registered for less than 139 credits (low credits registered category) and the students who registered for more than 148 credits (high credits registered category) are highly at risk for failure (83.4\% and $80.4 \%$ at risk respectively). Students in the average category (139.1 - 148 credits) have a higher chance of being academically successful (44.6\% at risk). This finding point to an optimum number of credits associated with academic success.

Analysis of variance (ANOVA) on the Levene's test howeve indicated that the variances are not homogenous and the Brown-Forsythe and Welch test was used to determine the difference between the three M-score categories and the number of credits that students register for. Both tests point to a highly significant difference in the number of credits registered between the three M-score groups, which is consistent with the standard ANOVA results $\left(p=0.002, F_{(2)}=.551\right)$. The Games-Howell method was used in Post hoc tests because homogeneity of variance did not hold in the data, which was determined by the Levene's test. The Games-Howell method indicates significant differences between students in the low and high M-score category $(p \leq 0.001)$, but not between low and average or between average and high M-score categories.

Influence of credits registered. A cross-tabulation, this time with credits registered differentiated by race, point to a significant difference with a Pearson Chi-square $<0.001$, $d f(2)$. The cross-tabulation indicate that almost half of the black students are clustered in the low credits registered group (48.5\%), while only $28.6 \%$ of white students are clustered in the low credits registered group. When comparing the M-score category and race, the results indicate that $35.1 \%$ of black students are clustered in the low M-score category and $51.5 \%$ of black students are clustered in the average M-score category. This indicates that a number of the black students in the average $\mathrm{M}$-score category and possibly the high M-score category are clustered in the low credits registered category (a lower credit load), even though black students show an ability to register for more credits based on their high school achievement.

\section{Discussion}

The overall student model, as well as the model of the black and white students shows that high school achievement (M-score) is the single best predictor of academic success, which corresponds with various research findings (Astin, 1975; Astin \& Oseguera, 2005; Camara, 2005b; Sternberg \& Grigorenko, 2002). Both the beta weights and zero-order correlations of the three models point to an average to strong positive relationship between $\mathrm{M}$-score and academic success. Thus indicating that students with low M-scores are extremely at risk for failure and students with high M-scores are most successful academically.

M-score is a marginally stronger predictor in the case of white students than of black students. This in spite the fact that black students from the overall student sample, registered at a Historically White Afrikaans Institution are performing academi- cally better that their white counterparts at first-year level. Notwithstanding the fact that large numbers of black students in South Africa are still entrenched in an impoverished environment and those poorer resourced schools contribute to a lack of academic preparedness of students (Scott et al., 2007; Scott, 2009; CHE, 2009). This finding is surprising given the disparity evident in the literacy levels of households, socio-economic status and academic school environment of black students in the past, compared to white students (Jones, Coetzee, Baily, \& Wickham, 2008; Van Heerden, 1997). According to Jones et al. (2008) these factors are still present to some extent today. The relatively superior achievement of the black students may be explained by the fact they are bicultural, and able to access a lot more learning resources than others with lower levels of cultural adaptability. According to Sedlacek (2004), black students who understand the "system" have higher academic achievement and are more able to adjust to a Historically White Institution than those who do not. These students have developed an ability to balance the cultural or racial demands of the system where they can address racial issues that might affect their studies (Sedlacek, 2004).

Another possible explanation relates to a positive shift in the socio-economic status of many black people in South Africa which indicates that the artefacts that are necessary to stimulate learning and the development of children are more so part of their domestic environment. Black children also have greater access to quality schools and have active role models from the same cultural background which can counter the so called 'stereotype threat' (Rodgers \& Summers, 2008). Stereotype threat refers to internalised biased beliefs about a group that negatively influences the intellectual functioning and identity development of an individual belonging to that group (Rypisi, Malcolm, \& Kim, 2009). Sedlacek (2004) and Rypisi et al. (2009) report that African-American and female students are usually negatively influenced by stereotype threat. Nonetheless, there is evidence to suggest that black students entering universities have high academic ability and is a highly selective group (Scott, 2009). Black students could therefore achieve academically better than white students, irrespective of the type of institution.

Black students tend to register for fewer credits than white students with the same high school academic achievement (measured by M-score). This finding is contrary to Van Heerden's (1997) study, which indicated that black students underestimate the workload and the quality of the work required. It seems that black students from the present study are cautious when loading their programme with credits and this behaviour is actually benefitting the black students with higher academic success in the first-year, compared to white students.

Goal orientation has a positive linear relationship with academic success, thus indicating that students with higher goal orientation scores are more successful academically. The research results are confirmed by various researchers (Bean \& Eaton, 2000; Conley, 2007; Pintrich \& De Groot, 1990). Students with high goal orientation scores will be able to plan their learning tasks, have self-evaluation skills which provide the drive to plan and monitor goals and provide feedback as to how the student is doing in relation to academic achievement and goals. Goal orientation is a significant predictor of academic success in the multiple regression analyses for the overall student group as well as for the white students but not for the black students. The finding of Rodgers and Summers (2008) confirm that motivational constructs such as goal orientation are not the 
same for African-American students as it is for white students. But, learning processes and outcomes for Americans do not necessarily translate to Africans.

Parental education at the University of Pretoria produced significant relationships for the white and black students' multiple regression analysis, but not for the overall student group. The directions of the relationships between black and white students are different. That is, white students' parent(s) who did not study at the University of Pretoria or whose parents have no university degree, are marginally more successful than the white students whose parents studied at the University of Pretoria. White students traditionally attend historically privileged schools and usually are well prepared for higher education. For that reason, first-generation students are thus able to be just as successful academically as second-generation students if they are well prepared academically at school level.

The opposite is relevant for the black students. Black students whose parent(s) studied at the University of Pretoria are marginally more successful than black students whose parent(s) did not study at the University of Pretoria or who have no university degree. It seems that in the case of black students, the parents' familiarity with the university environment contributes to the students' academic success. These parents are able to provide additional motivational support to students (Jones et al., 2008; Johnston, 2000).

\section{Limitations of the Study and Suggestions for Future Research}

The limitations of the study mainly relate to the student sample that was chosen. Black students were slightly under-represented in the sample, compared to white students. Second, students from only one cohort from the Faculty of Economic and Management Sciences were assessed. The study could have benefited from more than one year's cohort, or alternatively across faculties in a single year to determine if the same trends are found. Future studies should expand the sample from one faculty to the population of first-year students registered at the institution. This will determine whether the trend of academic achievement of black and white students persists at faculty level or not and whether the predictive value of the readiness characteristics continue across faculties among the two racial groups or not.

\section{Conclusion}

The results suggest that academic and non-academic variables predict academic success, although not equally for different racial groups. The variables that predict academic success for the white students are similar to that of the overall student model and one can reason that the predictor variables in the overall student model are highly influenced by the white students' profile. Nevertheless, knowledge of the between and within-group differences implies that in practice the readiness characteristics that predict academic success can be used to plan interventions of potentially at-risk students by group.

\section{References}

Astin, A. W. (1975). Preventing students from dropping out. San Francisco, CA: Jossey-Bass.

Astin, A. W., \& Osequera, L. (2005). Pre-college and Institutional Influences on degree attainment: Theoretical developments in the study of college student departure. In A.
Seidman (Ed.), College student retention: Formula for student success (pp. 245-276). Westport, CT: Praeger.

Bean, J., \& Eaton, S. B. (2000). A Psychological model of college student perception. In J. M. Braxton (Ed.), Reworking the student departure puzzle (pp. 48-61). Nashville, TN: Vanderbilt University Press.

Beck, H. P., \& Davidson, W. D. (2001). Establishing an early warning system: Predicting low grades in college students from survey of academic orientations scores. Research in Higher Education, 42(6), 709-723.

Braxton, J. M., \& Hirschy, A. S. (2005). Theoretical developments in the study of college student departure. In A. Seidman (Ed.), College student retention: Formula for student success (pp. 61-87). Westport, CT: Praeger.

Bunting, I. (2006a). The higher education landscape under apartheid. In N. Cloete, P. Maassen, R. Fehnel, T. Moja, T. Gibbon \& H. Perold (Eds.), Transformation in higher education: Global pressures and local realities (pp. 35-52). Dordrecht, The Netherlands: Springer.

Byrd, K., \& MacDonald, G. (2005). Defining college readiness from the inside out: First generation college-student perspectives. Community College Review, 33(1), 22-37.

Camara, W.J. (2005b). Broadening predictors of college success. In W. J. Camara \& E. W. Kimmel (Eds.), Choosing students: Higher education admissions tools for the 21st century (pp. 81-105). Mahwah, NJ: Lawrence Erlbaum Associates.

Conley, D. T. (2005). Proficiency-based admissions. In W. J. Camara \& E. W. Kimmel (Eds.), Choosing students: Higher education tools for the 21st century (pp. 313-330). Mahwah, NJ: Lawrence Erlbaum Associates.

Conley, D.T. (2007). Redefining college readiness (Vol. 3). Eugene, OR: Center for Educational Policy Research, University of Oregon.

Council on Higher Education (CHE). (2004). South African Higher education in the first decade of democracy. Pretoria, South Africa: Author.

Council on Higher Education (CHE). (2009). Higher Education Monitor: The state of higher education in South Africa. Pretoria, South Africa: Author.

Geiger, M. A., \& Cooper, E. A. (1995). Predicting academic performance: The Impact of expectancy and needs theory. Journal of Experimental Education, 63(3), 251-263. Retrieved December 15, 2009, from Academic Search Premier.

Hawkins, V. M., \& Larabee, H. J. (2009). Engaging racial/ethnic minority students in out-of-class activities on predominantly white campuses. In S. R. Harper \& J. Quaye (Eds.), Student engagement in higher education: Theoretical perspectives and practical approaches for diverse populations ( $\mathrm{pp}$. 179-188). New York, NY: Routledge.

Johnston, V. (2000, September). Identifying students at risk of non-progression: The development of a diagnostic test. Paper presented at the annual British Educational Research Association (BERA) Conference held at BERA, Cardiff.

Jones, B., Coetzee, G., Baily, T., \& Wickham, S. (2008). Factors that facilitate success for disadvantaged higher education students. Rural Education Access Programme (REAP). Unpublished document available at www.reap.org.za

Joubert, J. M. (2002). 'n Teoretiese Model vir die Toepassing Van Self-Gereguleerde Leer met Metakognitiewe 
Betrokkenheid as ' $n$ Tweede-orde Proses [A theoretical model for the application of self-regulated learning and meta-cognitive involvement in second-order process] (Unpublished doctoral thesis). University of Pretoria, Pretoria, South Africa.

Kuh, G. D., Kinzie, J., Buckley, J. A., Bridges, B. K., \& Hayek, J. C. (2007). Piecing together the student success puzzle. ASHE-ERIC Higher Education Report, 32(5). San Francisco, CA: Wiley.

Lemmens, J. (2010). Student's readiness for university education (Unpublished doctoral thesis). University of Pretoria, Pretoria, South Africa.

Palant, J. (2007). SPSS Survival Manual (3rd ed.). Berkshire, England: Open University Press.

Pintrich P.R., \& De Groot, V.E. (1990). Motivational and self-regulated learning components of classroom academic performance. Journal of Educational Psychology, 82, 33-40.

Rodgers, K. A., \& Summers, J. J. (2008). African American students at predominantly white institutions: A motivational and self-systems approach to understanding retention. Education Psychology Review, 20, 171-190.

Rypisi, C., Malcolm, L. E., \& Kim, H. S. (2009). Environmental and developmental approaches to supporting women's success in STEM fields. In S. R. Harper \& S. J. Quaye (Eds.), Student engagement in higher education: Theoretical perspectives and practical approaches for diverse populations (pp. 117-135). New York, NY: Routledge.

Scott, I. (2009). First-year experience as terrain of failure or platform for development? In B. Liebowitz, A. Van der Merwe, \& S. Van Schalkwyk (Eds.), Focus on First-year success: Perspectives emerging from South Africa and beyond (pp. 17-36). Stellenbosch, South Africa: African Sun Media.

Scott, I., Yeld, N., \& Hendry, J. (2007, October). A case for improving teaching and learning in South African higher education. Higher Education Monitor (No. 6). Pretoria, South Africa: Council on Higher Education.

Sedlacek, W. E. (2004). Beyond the BIG TESt: Noncognitive assessment in higher education. San Francisco, CA: Josey-Bass.

Seidman, A. (Ed.). (2005). College student retention: Formula for student success. Westport, CA: Praeger.

Schlossberg, N. K., Waters, E. B., \& Goodman, J. (1995). Counseling adults in transition: Linking practice with theory (2nd ed.). New York, NY: Springer.

SPSS.V17® Software. Statistical Package for the Social Sciences - South Africa. Capetoen, South Africa: Author.

Tabachnick, B. G., \& Fidell, L. S. (2007). Using multivariate statistics (5th ed.). Boston, MA: Pearson.

Tinto, V. (1993). Leaving college: Rethinking the causes and cures of student attrition. Chicago, IL: The University of Chicago Press.

Umalusi (Council for Quality Assurance in General and Further Education and Training). (2009). Maintaining standards report (part 1): Overview (July 2009). Pretoria, South Africa: Author.

Umalusi (Council for Quality Assurance in General and Further Education and Training). (2010). 2009 Maintaining Standards Report: Overview (May 2009). Pretoria, South Africa: Author.
Upcraft, M. L., Gardner, J. N., \& Barefoot, B. O. (2005). Challenging and supporting the first-year student: $A$ handbook for improving the first year of college. San Francisco, CA: Jossey-Bass.

Van Heerden, E. (1997). University education and African thought: Reflections on underachievement among some UNISA students. South African Journal of Ethnology, 20(2), 76-94. 
